\title{
Exploring Deep-Rock Mechanics through Mechanical Analysis of Hard-Rock In Situ Coring System
}

\author{
Jianan Li, ${ }^{1}$ Heping Xie, ${ }^{1,2}$ Ling Chen $\mathbb{D}^{1},{ }^{1}$ Cong $\mathrm{Li},{ }^{1,2}$ and Zhiqiang $\mathrm{He}^{1,2}$ \\ ${ }^{1}$ School of Mechanical Engineering, State Key Laboratory of Hydraulics and Mountain River Engineering, \\ College of Water Resource and Hydropower, Sichuan University, Chengdu 610065, China \\ ${ }^{2}$ Guangdong Provincial Key Laboratory of Deep Earth Sciences and Geothermal Energy Exploitation and Utilization, \\ Institute of Deep Earth Sciences and Green Energy, College of Civil and Transportation Engineering, Shenzhen University, \\ Shenzhen 518061, China \\ Correspondence should be addressed to Ling Chen; chenlingscu@scu.edu.cn
}

Received 2 July 2020; Revised 20 August 2020; Accepted 20 August 2020; Published 7 September 2020

Academic Editor: Fengqiang Gong

Copyright (c) 2020 Jianan Li et al. This is an open access article distributed under the Creative Commons Attribution License, which permits unrestricted use, distribution, and reproduction in any medium, provided the original work is properly cited.

Exploration of deep-rock mechanics has a significant influence on the techniques of mining and rock mechanics. Rock coring technique is the basic method for all rock mechanics study. With the increase of the drilling depth and increasing strength of the hard rock, how to obtain high-quality rock core through various coring techniques is an eternal work. Here an innovative method is applied to design the new coring system to maximize the efficiency of operation. The stress conditions or parameters of rock core in the coring are analyzed, and the mechanism of the core with in situ stress is shown in this paper. The conflict of the core and coring tool chamber is proposed for the innovative design. The innovative design method is fulfilled by the theory of inventive problem solving (TRIZ). An improved coring system for the full-length core with in situ stress was obtained with the solutions of improved coring mechanism, cutting mechanism, and spiral drill pipe.

\section{Introduction}

In the past, human activities are mainly on the subsurface range of the earth's surface, whose depth is less than $100 \mathrm{~m}$. However, with the development of the human civilization, people living on the earth's surface encountered a lot of limitations. The growth of human knowledge about earth's crust and the advancement in engineering helped mankind to study and analyze deeper parts of earth's crust. This steered the development of various industrial activities, such as coal mining and oil drilling. The activities in deeper parts of earth's crust have not only helped in better understanding of geoscience but also finding a lot of new resources for people, such as gas hydrate and geothermal energy [1-3]. At present, the mineral resources in the shallow part of the earth have been gradually exhausted, and the development of resources has been moving towards the deep part of the earth. However, the basic research on the deep development is not enough and the basic law is still unclear [4]. Further, coring methods provided a better understanding of the structure and stress distribution of rocks underground. Rock coring technique is the basic method for all rock mechanics because of its ability to provide the mechanical behavior, chemical characterization, and structure of rock and this information gives a better understanding of the structure and stress distribution of rocks underground [5]. All the information mentioned above has significant impact on rock engineering [6]. The rock core at the deep is the most important part of the earth's crust as it has or bears all geological information [7]. Based on the different conditions of underground, deep-rock coring techniques can be classified into three categories, that is, oil core drilling techniques, geological core drilling techniques, and scientific core drilling techniques [8]. According to the coring method, each method can be divided into wireline coring and coring by lifting drilling pipe [9]. As wireline coring has better efficiency and continuous coring ability, this method has wide application in hard-rock coring by vertical drilling. 
Based on the underground condition, different core barrel structures to obtain high-quality core are developed. However, the core always gets cracked or broken during the coring process due to stress developed when drilling, disking phenomenon, crack, and so on. Moreover, the core recovery method is still the main method for obtaining the main information of the underground condition, especially for the stress distribution in the core $[10,11]$. When drilling depth is increased, we can find that the strength of hard rock is also increased. As a result, core blocking occurs which poses a great challenge to drilling. Therefore, how to obtain highquality rock core is always an eternal work for a coring technique. The quality of core is not only limited by the coring technology but also by the strong crustal stress on the deep rock [12]. High ground stress is the main factor affecting the special mechanical behavior of deep rock $[13,14]$. It is well known that stresses are commonly assumed to be caused by primary and secondary sources. Assuming there is no man-made stress on the rock core, the core only has primary stress on it caused by the cumulative effect of events that happened in the geological history of the rock, for example, gravitational, tectonic, residual, and terrestrial stresses [15, 16]. For the hard rock, there is a little achievement in obtaining this primary stress or in situ stress in coring technique. In China, a key research project is proposed by the government to obtain the hard-rock core with in situ conditions. The ultrasonic drilling method is applied to reduce the stress relief in cutting. The exploration of the deep-rock mechanism was used to understand the challenges to be faced and the innovative method is applied to assist designers in finding the relevant knowledge in all research fields for designing the structures. This paper analyzed the stress conditions of rock core during the coring and showed the mechanism of the core with in situ stress. The structure is analyzed to fit this in situ stress condition and the conflict between core and coring tool chamber is proposed for the innovative design. The innovative design method is based on the theory of inventive problem solving (TRIZ) and some new methods are proposed by this theory. After comparison of these new structures in rock core mechanic analysis, the simulation work of rock core with in situ stress was studied to explore the contribution to deeprock mechanics. An improved coring system for full-length core with in situ stress was obtained with the solutions of improved coring mechanism, cutting mechanism, and spiral drill pipe.

\section{Mechanical Analysis in Rock Coring System}

The rock core with in situ conditions under a borehole is taken for the mechanical analysis. As the rock core with in situ coring needs to retain stress distribution as in the underground, then the contact between core barrel and rock core will be very hard. At the same time, contact force needs to be in equilibrium with rock core in the in situ state. Therefore, to obtain a hard-rock sampler, a simple method is used in which a steel cylinder inbuilt with drill bits bore a rock mass up to the required depth based on the conditions of the rock structure [6]. During coring, lubricating oils will be used for cooling purposes and when coring operation is over, the bored holes are assumed to be filled with lubricants or fluids in this coring or drilling method. Therefore, the core force analysis is shown in Figure 1.

As mentioned in the Introduction section, the general idea of coring with in situ conditions should keep the force between core barrel and rock core in equilibrium. Because of the in situ stress, there is always a plastic-elastic effect zone, as shown in Figure 1. The forces developed during operations are mainly caused by gravity $G$, friction force $F_{f}$, core hydrostatic pressure $P_{0}$, and the in situ stress of deep rock. The interaction and influence of forces determine the efficiency and quality of core. The mechanical analysis is presented to find the mechanism for low quality of core. In the deep-rock environment, the primary stress of the rock core is the stress in the vertical direction, which is equal to the pressure generated by the weight of the rock mass in the vertical direction and is expressed as

$$
\sigma_{v}=\gamma \cdot h
$$

where $\gamma$ represents the volume weight $\left(\mathrm{N} / \mathrm{m}^{3}\right)$ and $h$ is the depth of the core location $(m)$.

In the system with existing coring tool and the borehole coring technology, the water pressure in the vertical direction of the core is equal to the stress in its vertical direction, which can be expressed as

$$
\sigma_{v}=\rho_{w} g h+p_{0}
$$

In the above equation, $\rho_{w}$ denotes the density of water, $g$ denotes the acceleration of gravity, and $p_{0}$ indicates the pressure value of water coming out of the horizontal surface under hydrostatic pressure.

The strength of the core barrel and its related structure should be greater than the damage intensity force at the core level according to the pressure characteristic of the rock core.

While the core is subjected to the original horizontal stress, in the vertical direction, the force due to friction and gravity will cause the core to become shorter and thicker. In addition, because the core is located in the core barrel, the horizontal deformation is restrained by the core barrel, thus increasing the horizontal stress. This change causes not only increases in the frictional force when the core slides into the core barrel, but also increases in the original stress on the core barrel.

In this paper, the influence of the increase of the horizontal stress of the core is analyzed. According to distribution law of horizontal principal stress with depth [17], the horizontal stress $\sigma_{h}$ of the core is mainly from the stress in the vertical direction. At the same time, the magnitude of the horizontal stress will increase with the increase of core depth and gradually turn into a major stress, which can be expressed as

$$
\sigma_{h}=0.0238 h+7.648
$$

In addition, because the rock core is squeezed into the core barrel, the force analysis of the core will need to be reanalyzed, and the analysis results are shown in Figure 2.

In the vertical direction, the core is subjected to the frictional force generated by the friction force $F_{f}$ and by its 


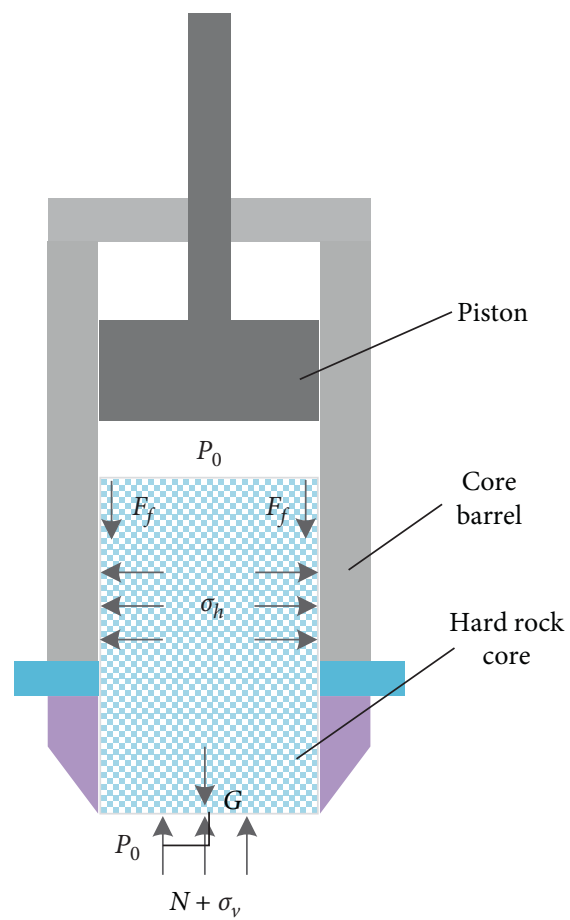

(a)

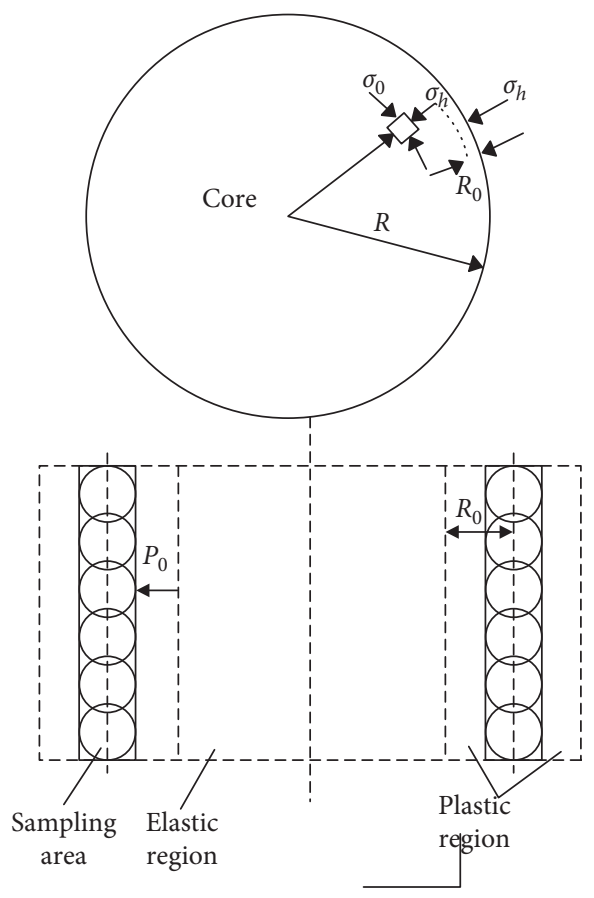

(b)

Figure 1: Mechanical analysis of coring system. (a) The schematic diagram of the core axial force under the core bit structure and (b) the radial force of the core.

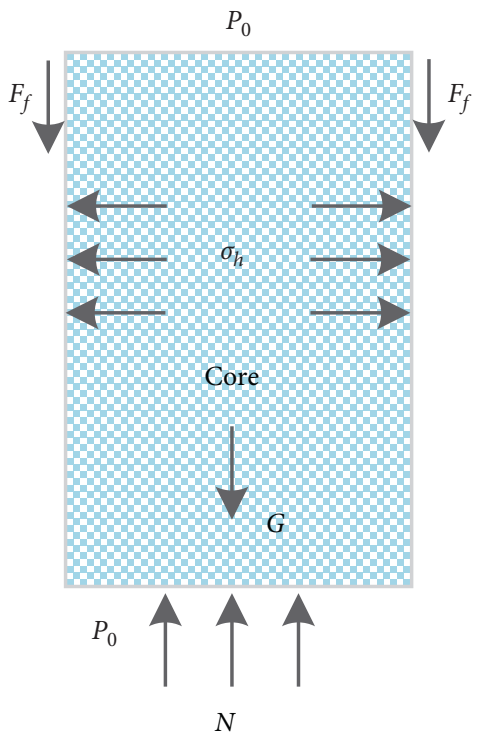

Figure 2: Mechanical schematic diagram of rock core.

own gravity. As the core length $l$ increases, the vertical support force $F_{N}$ is also increasing, and its concrete force can be expressed as

$$
F_{N}=\pi d l \cdot \sigma_{h} .
$$

In addition, because the rock core is surrounded by the water, the gravity of the core in the water can be expressed as

$$
G=\frac{\pi d^{2} g h\left(\rho_{R}-\rho_{w}\right)}{4} .
$$


The water environment of the core is in the range of core length, the pressure change is very small, and the water pressure on the core will be the same. When the core enters the core barrel, as the depth of sampling increases, the corresponding friction force will increase, the friction coefficient $\mu$ is about 0.35 , and the friction force can be expressed as

$$
F_{f}=\mu \cdot F_{N}=\pi \mu d l \cdot \sigma_{h} .
$$

At this point, the total support force $N$ of the rock core can be expressed as

$$
N=G+F_{f}=\frac{\pi d^{2} g h\left(\rho_{R}-\rho_{w}\right)}{4}+\mu \pi d l \cdot \sigma_{h} .
$$

Though the rock core is in the core barrel, the condition of rock core is related to deep rocks in the earth.

Therefore, the bottom of the core is the most vulnerable deformation position, and the stress at the bottom of the core can be expressed as

$$
\sigma_{N}=\frac{4 N}{\pi d^{2}}=g h\left(\rho_{R}-\rho_{w}\right)+\frac{4 l}{d} \cdot \mu \sigma_{h}
$$

If the strength of the bottom volume of the rock core reaches the yield strength of the core, the rock core will have a severe plastic deformation when it enters the core barrel. As the extrusion intensifies, the core will be damaged. Therefore, the yield strength at the bottom of the core is the maximum or limit stress at the entry point of the rock into the fidelity cylinder. According to the limit conditions, the rock core can enter the length of the core cavity when the yield strength occurs and the limit length can be expressed as

$$
\sigma_{N}=\frac{4 N}{\pi d^{2}}=g h\left(\rho_{R}-\rho_{w}\right)+\frac{4 l}{d} \cdot \mu \sigma_{h}<\sigma_{Y} .
$$

According to formula (9), the limit length of the core rock that can enter barrel is given as follows:

$$
l<\frac{d}{4}\left(\frac{\sigma_{Y}-g h\left(\rho_{R}-\rho_{w}\right)}{\mu \sigma_{h}}\right) .
$$

In the traditional penetration coring device, limestone is assumed for the coring rock in the deep underground. The other parameters of the rock core conditions are shown in Table 1.

Substitute the above parameters into equation (10) and obtain the limit length $l<102 \mathrm{~mm}$. In the actual coring process, a part of the core is usually lost, so it is impossible to make a standard core with length of $100 \mathrm{~mm}$. It is necessary to study how to obtain longer cores.

In order to obtain the in situ conditions of rock core, the contact point of hard rock and core barrel should be strong enough to keep the stress in horizontal direction. Taking the drilling system as a base for the sampling mechanism, cutting area, debris removal, and contact form of core barrel should be optimized to improve the core recovery rate and obtain better core morphology, as shown in Figure 3 and Table 2. However, there is a conflict relation between hard contact and high friction at the entry point of hard-rock core into core barrel. For the better design of coring system, the innovative design method is applied. Moreover, the solution of the new design is also applied to the method of knowledge engineering to obtain the exact and required knowledge for this new design.

\section{Design Solution Strategy of Hard- Rock Sampler}

As core drilling process involves various complex functions such as drilling, sampling, storage, and fidelity and in the process of the designing and implementation of the hardrock sampler, a series of design conflicts that are more difficult to break through and solve usually exist. If we want to maintain the integrity of the sampled drill core strength better during design, other parameters related to the modified structure may be affected by the change of drilling and mining methods. The result may cause the device to have a negative impact on other performances and create a conflict. Relying on the design criteria that are summed up by the predecessors often is not a good way to start with. The above problems can be solved easily using the conflict resolution theory: theory of inventive problem solving (TRIZ) [18].

The innovation of various equipment structures is fundamentally to solve or improve the design problem and create a new competitive solution. Conflicts generally exist in design; particularly, technical conflicts and physical conflicts are the main forms of existence. It is universally believed that, in the process of improving the conflict problem, it is not possible to solve the problem completely but can reduce the degree of conflict with a compromise formula [19]. In the actual problem analysis process, in order to facilitate the definition of a technical conflict in a system, TRIZ theory transforms a specific problem into a standard TRIZ problem with the help of 39 general technical parameters. Then, the technical conflict is solved by the invention principle and the physical conflict is solved by four separate principles [20].

Here, when mechanical properties, mainly friction force, of deep hard are analyzed, there is a need to reduce and eliminate the effect of drill core pile and the degree of distortion by designing a new type of mechanical device. In order to solve the design problem and conflict of the hardrock sampler, a set of innovation oriented design solution strategies should be set up. Based on TRIZ conflict resolution theory, substance-field model, the design strategy process of a hard-rock sampler as shown in Figure 4 can be established, and it includes the following parts [21-23]: (1) the stage of analyzing drilling module problem: based on the mechanical properties and the fidelity coring requirements, the opportunity recognition and problem discovery are realized, and the engineering definition of the problem is completed; (2) the stage of problem transition and conflict definition: problem-oriented conflicts are resolved, then expressing the defined engineering problems in the way of demand and clear solution direction; (3) the stage of innovation design: we usually establish substance-field model 
TABLE 1: The core parameters for calculation.

\begin{tabular}{lcccccc}
\hline $\begin{array}{l}\text { Core diameter } \\
(\mathrm{m})\end{array}$ & $\begin{array}{c}\text { Compressive strength } \\
(\mathrm{Pa})\end{array}$ & $\begin{array}{c}\text { Acceleration due to gravity } \\
(\mathrm{N} / \mathrm{kg})\end{array}$ & $\begin{array}{c}\text { Depth of core } \\
(\mathrm{m})\end{array}$ & $\begin{array}{c}\text { Water density } \\
\left(\mathrm{kg} / \mathrm{m}^{3)}\right.\end{array}$ & $\begin{array}{c}\text { Rock density } \\
\left(\mathrm{kg} / \mathrm{m}^{3)}\right.\end{array}$ & $\begin{array}{c}\text { Friction angle } \\
\left({ }^{\circ}\right)\end{array}$ \\
\hline 0.05 & $9 E+07$ & 9.8 & 1,000 & 1,000 & 2,000 & 35 \\
\hline
\end{tabular}

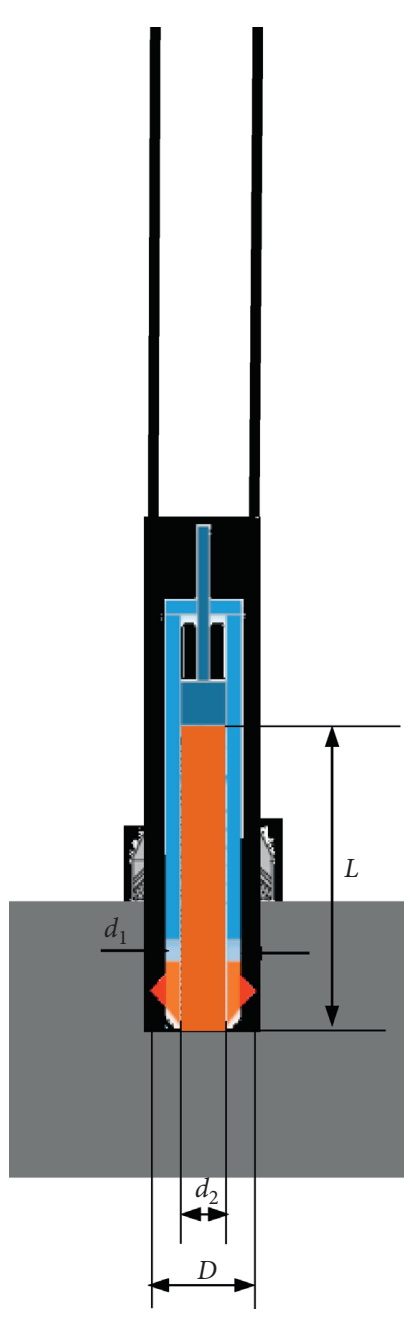

Figure 3: Structural parameters of coring system.

TABle 2: Structural parameters and optimization objectives of traditional coring.

\begin{tabular}{lc}
\hline Key parameter & Optimization objective \\
\hline$D$ & Reduce \\
$d_{1}$ & Reduce \\
$d_{2}$ & Constant \\
$L$ & Increase \\
$F_{f}$ & Reduce \\
Coring mechanism & Rotary drilling \\
\hline
\end{tabular}

and conflict solutions for the design of hard-rock sampler and the separation principle; the invention principle or the standard solution can be used to reduce the solution range according to the specific conflict characteristics; (4) the stage of project evaluation and verification: we turn the design plan into an application plan and judge its effectiveness in combination with manufacturing and existing environment. If a conflict is generated, return to the design phase and solve the conflict.

As an important tool for description and analysis of TRIZ theory, substance-field model decomposes the function of the system into two substances $\left(S_{1}, S_{2}\right)$ and a field $(\mathrm{F})$ [24]. A function consists of the three components, that is, two substances and a field. A matter achieves a specific function by field interaction. The conflict between the three elements of the substance-field model and the expected effect can be solved by using 6 general solutions and 76 standard solutions. It usually consists of four types, which are useful and full-interaction models, useful but insufficient interaction models, useful but excessive interaction models, and harmful interaction models. The functional components of the core module of the hard-rock sampler can be described in the form of the substance-field model as follows:

$$
\left\langle F, S_{1}, S_{2}\right\rangle
$$

here, $F$ represents the way of drilling and collecting the core module (embodied in the way of the field), $S_{1}$ represents core module of hard-rock sampler, and $S_{2}$ represents drilling material like hard rock. The substance-field model of hardrock sample belongs to the second type of useful but inadequate interaction models. Materials $S_{1}$ and $S_{2}$ can be defined as a useful but inadequate trigger for design elements and performance design elements. Field $F$ can be defined as a useful but inadequate structural design performance.

The core structure of the hard-rock sampler is designed to maximize the horizontal pressure characteristics of the in situ core and to improve the strength and integrity, reduce the pressure stress caused by friction in vertical direction, reduce the constraints imposed on the core in horizontal direction of the fidelity coring tube, and weaken the change of the horizontal stress component in the core. Generally, the solving process of this method is as follows: choose solution tools, choose a solution synthetically, and judge whether the solution is complete and effective.

\section{Design Analysis of the Hard-Rock Coring System}

4.1. Innovative Design Methods. To maintain the integrity of the in situ coring pattern of the hard-rock sampler in deeprock mass environments, we use the abovementioned design flow to improve the design of hard-rock sampler by drilling recovery collection module. According to processes (1) and (2), the design problems are defined and the design requirements are analyzed. In the traditional drilling, the core sample is subjected to the existing horizontal stress, and the 


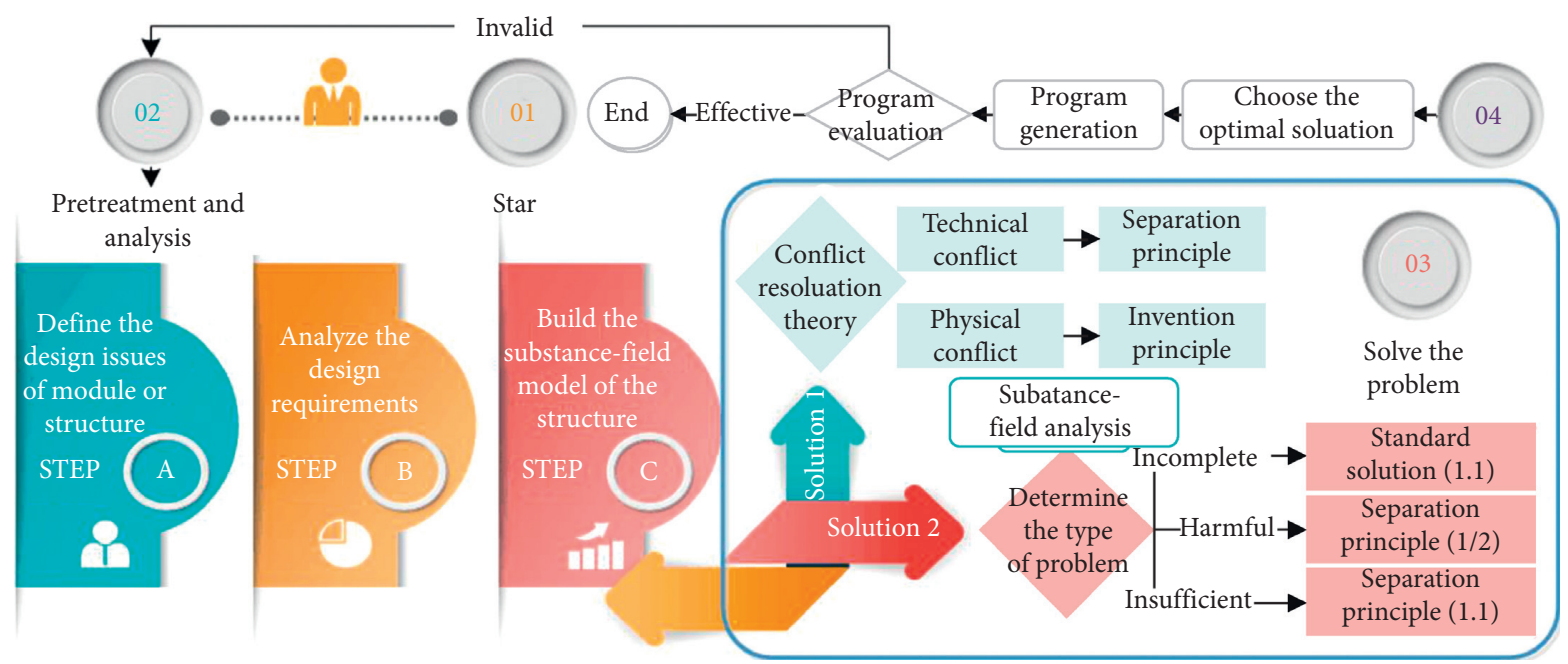

FIGURE 4: Design process of core system based on TRIZ conflict resolution theory-substance-field model.

compressive stress caused by the friction and gravity force in the vertical direction, which causes the core to become shorter and thicker. The core is located in the fidelity core barrel and the horizontal deformation is restrained by the core barrel, causing the horizontal stress component in the core to change. The size of the change not only causes the frictional force of the core sliding into the core barrel to increase but also changes the original stress state of the core barrel. The above analysis shows that the core is subjected to the friction generated by the extrusion force $F_{N}$ in the vertical direction. As the coring length increases, the component $N$ in the vertical direction also increases:

$$
F_{N}=\pi d l \cdot \sigma_{h} .
$$

When improving the design, frictional forces are mainly taken into account. Friction is the main force to keep the core fixed and is due to the basic physical contact between two bodies, as shown in Figure 5. However, the friction force also changes the force distribution of the core, resulting in the pile effect of the core and the increase of in situ distortion of the core. It is hoped that the process of the hard-rock sampler drilling and collecting module can improve the other mechanical properties by reducing the extrusion $F_{N}$, the friction force $F_{f}$, and the stress $\sigma_{h}$ while ensuring the core-taking length.

For the existing mechanical characteristics, the method of reducing friction according to the core characteristics can be divided into the following aspects: structure, contact medium, and movement control method. According to processes (1) and (2), the substance-field model of the hard-rock sampler is established. As shown in Figure 6, as the existing structure can only perform coring operations and its effect on maintaining the original mechanical properties is not obvious, the type of the substance-field analysis model should be a useful but not sufficient interaction model. This type can adopt the standard solutions of the second and the third class of the substance-field model, including 23 standard solutions of "enhanced object field model" and 6 standard solutions of "transformation to supersystem or microlevel," further reducing the standard solution space, and adopting comprehensively conflict resolution theory and substance-field model to improve the effectiveness and efficiency of the solution.

Classical conflict matrix can be based on the design of the system to produce two conflicting technical parameters, so that the innovative design can be found out from the invention principle of the conflict directly from the matrix table and using the principle to solve the problem $[25,26]$.

According to the analysis of the problems, the determinants of hard-rock sampler conflict parameter to be improved are determined to reduce the extrusion force $F_{N}$, the friction force $F_{f}$, and the stress $\sigma_{h}$, but the depth of the core conflicts with it (the contact area between the core and the core barrel during the movement), so refer to 39 common technical parameter definitions: hope to improve the parameters (10) force, (11) stress and pressure, deteriorating parameter, and (5) the area of the moving objects. Corresponding to the theory of TRIZ in Table 3, the collision matrix is queried.

Application solution is designed by comprehensively analyzing the solution of the invention principle and the standard solution of the substance-field analysis:

$$
\sigma_{N}=\frac{1}{n} \cdot \frac{4 N}{\pi d^{2}}=\frac{1}{n} \cdot\left[g h\left(\rho_{R}-\rho_{w}\right)+\frac{4 l}{d} \cdot \mu \sigma_{h}\right]<\sigma_{Y} .
$$

4.2. Innovative Design of Coring Mechanism. As the whole system is divided into $n$ parts, each part cannot yield the rock core, and the new structure has the ability to obtain the nodamage core. The principle of invention (19) periodic effect suggests replacing continuous action with periodic action or impulse action, and the principles of invention (15) dynamic characteristics prompts to separate objects so that its various parts can change the relative position. The second standard solution prompted S2 (core barrel) separation and get the design. (1) The design of penetration coring is improved to self-advancing rotary drilling and coring; at the same time, the drill pipe body is separated from the core barrel, and the core barrel made of a new material with smaller friction coefficient is separated from the rock core, so as to minimize the drilling disturbance to 


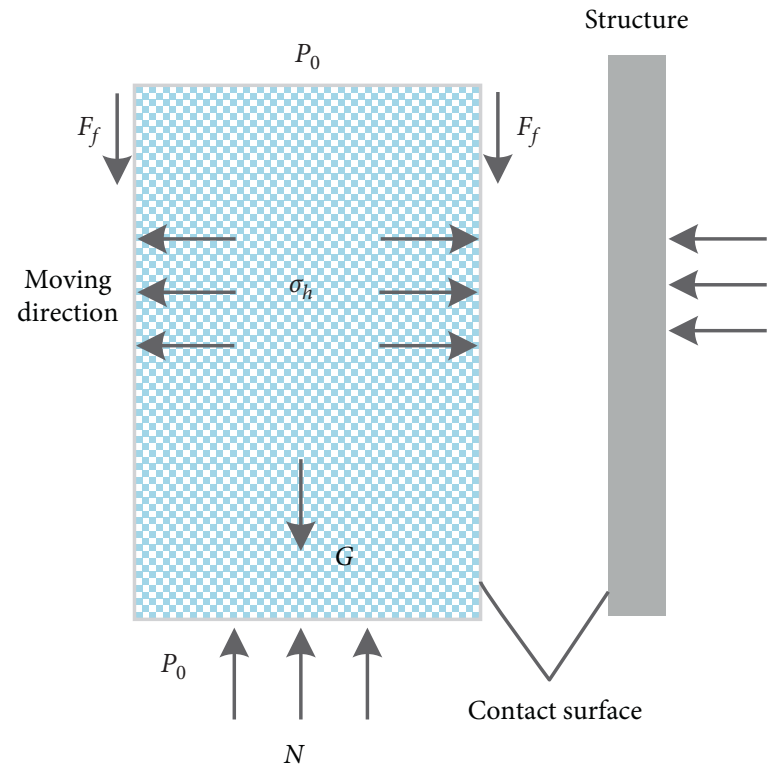

Figure 5: The distribution of elements for innovative design by mechanical analysis.

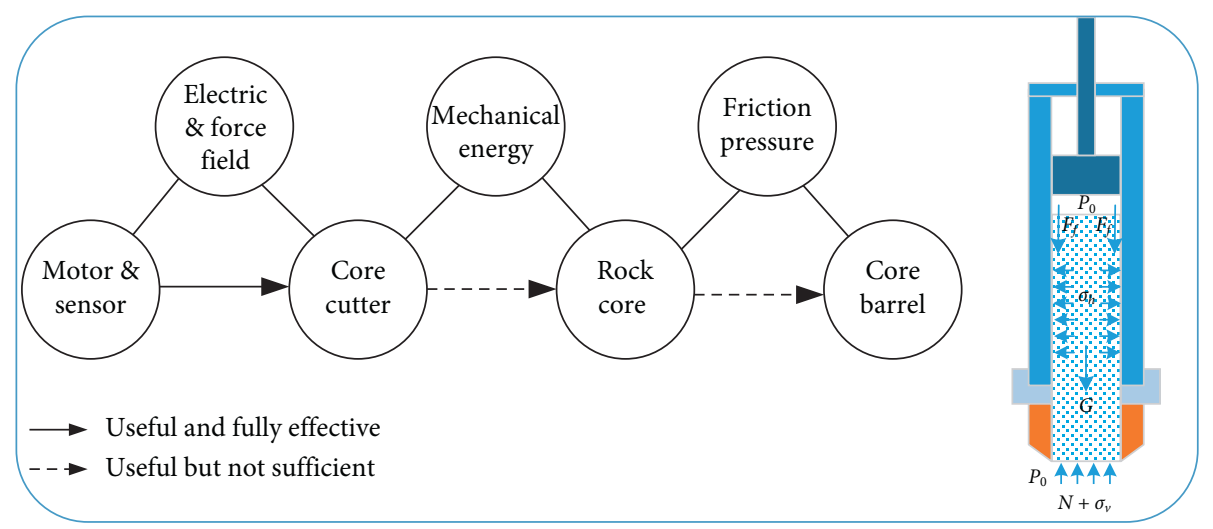

Figure 6: Substance-field model of the hard-rock sampler drilling.

TABLE 3: Hard-rock sampler drilling conflict matrix.

\begin{tabular}{|c|c|c|c|}
\hline Types & Improved parameters & Deteriorating parameters & Invention principle \\
\hline Technical conflict & (10) Force & (5) The area of the moving objects & $\begin{array}{l}\text { (19) Periodic effect } \\
\text { (10) Prerole } \\
\text { (15) Dynamic characteristics } \\
\text { (10) Prerole }\end{array}$ \\
\hline Technical conflict & (11) Stress and pressure & (5) The area of the moving objects & $\begin{array}{c}\text { (15) Dynamic characteristics } \\
\text { (36) Phase change } \\
\text { (28) Replace with mechanical system }\end{array}$ \\
\hline
\end{tabular}

the core and reduce the friction, as shown in Figure 7. (2) Principle of multistage and equal diameter cutting is designed to complete the rock cutting step by step. The outer diameter of new reaming tool is almost the same as that of drill pipe body, while the outer diameter of common core bit is about $5 \mathrm{~mm}$ larger than that of drill pipe. Taking the design in Table 4 as an example, the cutting area of new reaming design is about $30 \%$ lower than that of traditional blade design [27]. (3) The new design reduces the annulus area of cuttings when returning, which causes cuttings-sticking or friction increasing as cuttings-entering the core barrel. According to the principle of innovation (28), the spiral core drill pipe is 


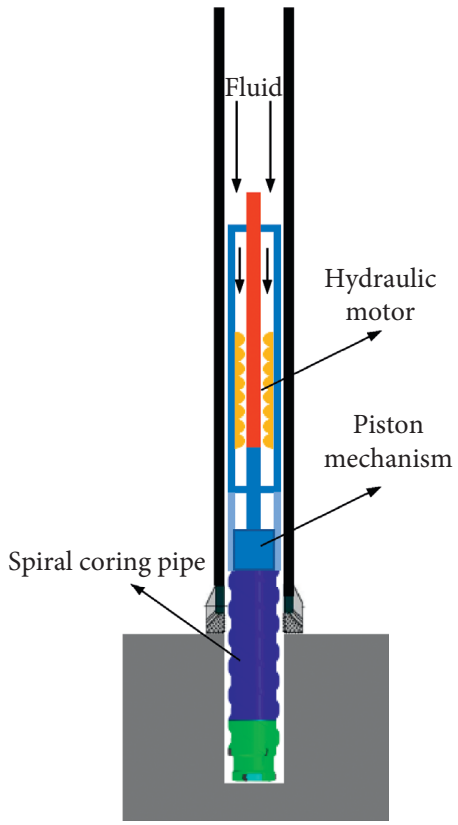

(a)

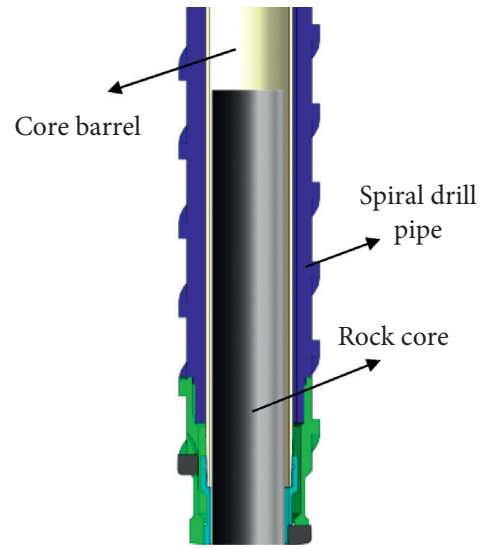

(b)

Figure 7: Innovative design of coring mechanism. (a) Self-advancing rotary drilling and coring. (b) Assembly relationship of drilling components.

TABle 4: Structural parameters of coring bit assembly.

\begin{tabular}{lccccc}
\hline Design method & $d_{1}(\mathrm{~mm})$ & $D_{1}(\mathrm{~mm})$ & $D_{2}(\mathrm{~mm})$ & Reaming area $\left(\mathrm{mm}^{2}\right)$ & Area reduction $(\%)$ \\
\hline Traditional design & 80 & 89 & 94 & 1,913 \\
Innovative design & 80 & 89 & 90 & 1,335 \\
\hline
\end{tabular}

TABLe 5: Drilling parameters.

\begin{tabular}{lcc}
\hline Speed & Weight on bit (WOB) & Circulation rate \\
\hline $300 \mathrm{r} / \mathrm{min}$ & $180 \mathrm{~kg}$ & $40 \mathrm{~L} / \mathrm{min}$ \\
\hline
\end{tabular}




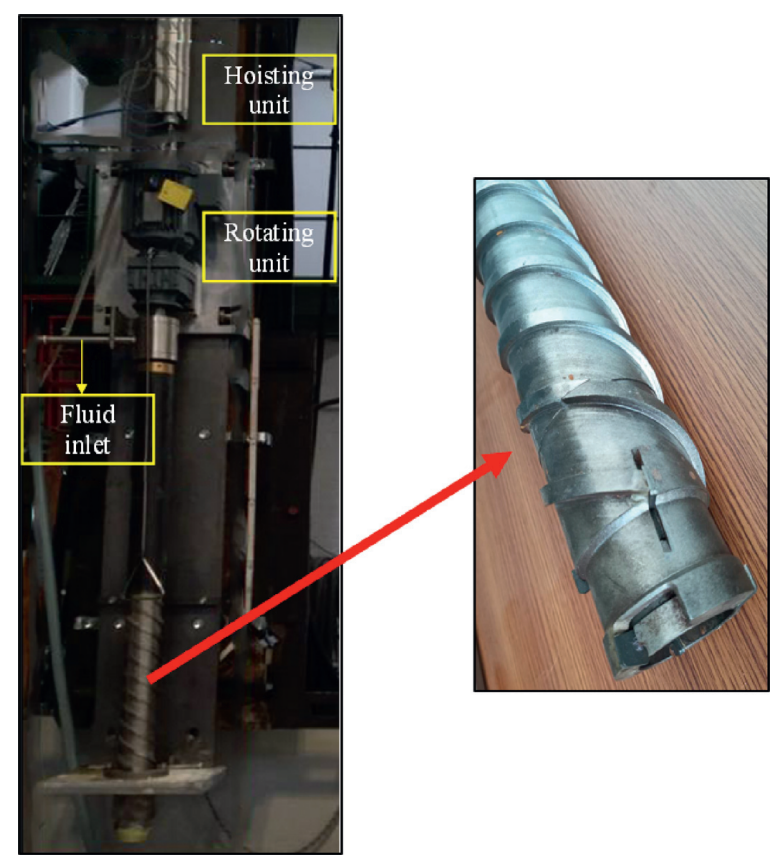

FIgURE 8: Experimental equipment and coring bit assembly.

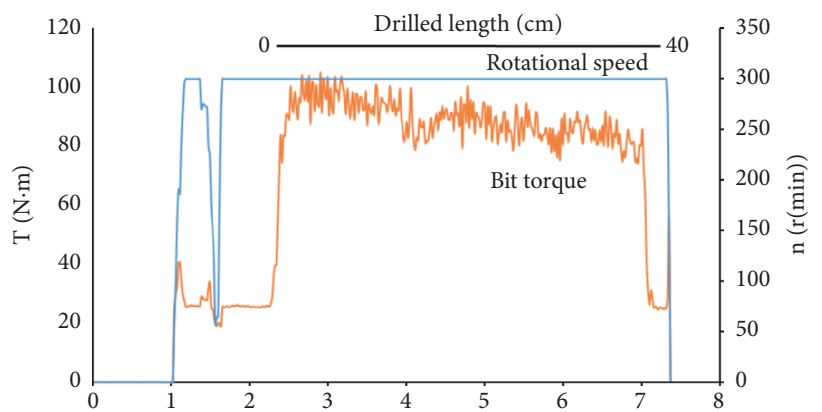

FIgURE 9: Drilling parameters of marble.

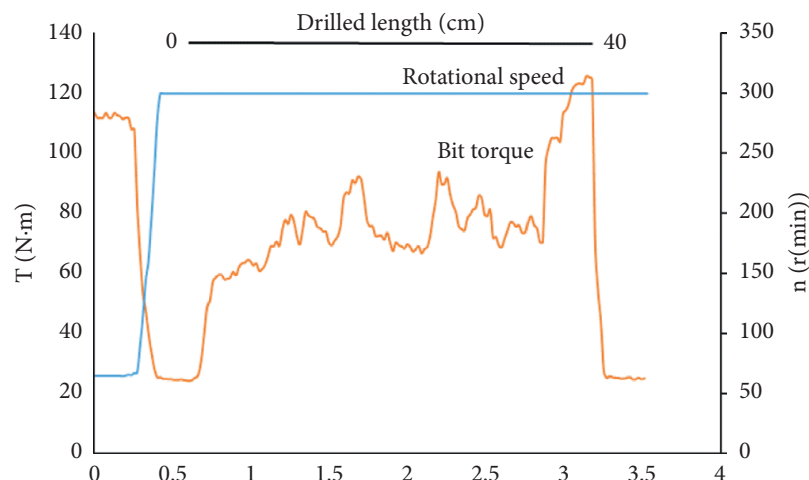

Figure 10: Drilling parameters of dolomite. 


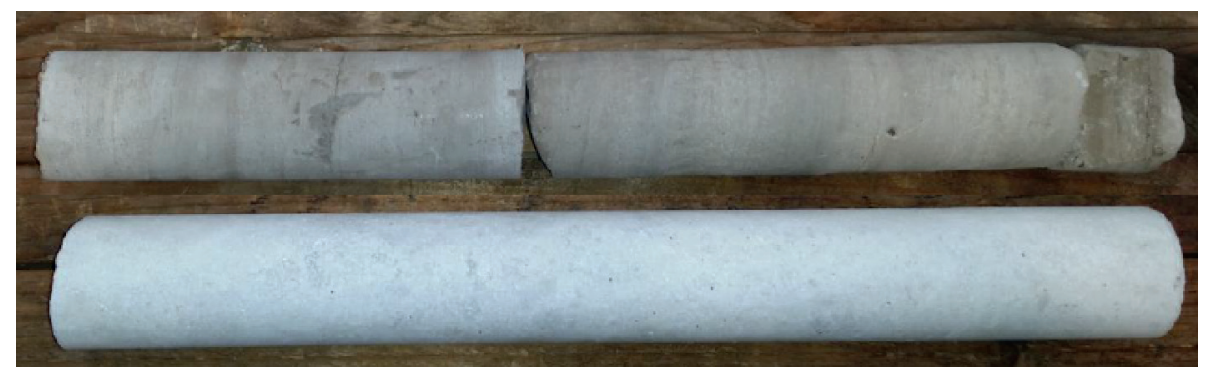

Figure 11: Recovered core (bottom: marble; Top: dolomite).

designed innovatively to increase the return channel, and the spiral mechanism is used to increase the return force of cuttings and the drilling force of core bit.

\section{Experimental Study on Rotary Drilling and Coring System}

In order to experimentally analyze the dynamical behavior of new coring system, a drilling test on coring bit assembly in design was conducted, which was the foundation of in situ coring system designing.

5.1. Experimental Equipment and Parameters. As shown in Figure 8 , the experimental equipment mainly includes the following: (1) rotating unit: because of the limitation of indoor space, electric motor is used instead of hydraulic motor; (2) hoist unit: it provides downward drilling power and hoist coring bit assembly to obtain rock core; (3) circulation equipment: it is used to assist the upper return of rock cuttings and maintain the liquid lubrication between the core and the core barrel at a certain pressure. The main drilling parameters are shown in Table 5.

5.2. Result Analysis. Two coring tests were undertaken in marble and dolomite. The calculated torque $(T)$ and rotational speed $(n)$ for dolomite and marble are presented in Figures 9 and 10 as a function of time. One core in marble and one in dolomite are shown in Figure 11.

As a uniform material, marble shows a relatively stable curve with little fluctuation of drilling torque. However, dolomite consists of nonuniform layers, and the results of drilling torque fluctuate violently. In the process of experiment, two $40 \mathrm{~cm}$ long cores of marble and dolomite were obtained, which proved the effectiveness of innovative design.

\section{Conclusions}

Due to the serious "stake effect" of hard-rock core in coring process, the in situ coring of the hard rock deeply underground $(>1000 \mathrm{~m})$ is a great challenge. This paper has done the mechanical analysis of the coring system of the hard rock and designed a new coring system for hard-rock core with in situ stress. In mechanical analysis, the core barrel has a serious friction problem with the hard-rock core. It not only causes the surface damage due to the friction force but also limits the core length for the condition of forming "stake effect." Based on this conflict by friction, four innovative structures are proposed to reduce the damage by friction and enhance the good effect to keep the in situ stress. The innovative design method of TRIZ is applied to improve the coring structure, contact medium of barrel and core, and motion control method. In this mechanical analysis, it is proved that all of these innovative designs can obtain the better quality of the hard-rock core than the traditional coring method. In the future, this new design method and coring system could be employed for the future exploration of the deep-rock mechanics.

\section{Data Availability}

The data used to support the findings of this study cannot be shared.

\section{Conflicts of Interest}

The authors declare that they have no conflicts of interest.

\section{Acknowledgments}

This work was supported by the National Natural Science Foundation of China (Grant nos. 51827901 and 51805340). The financial aids are gratefully acknowledged.

\section{References}

[1] K. Abid, G. Spagnoli, C. Teodoriu, and G. Falcone, "Review of pressure coring systems for offshore gas hydrates research," Underwater Technology, vol. 33, no. 1, pp. 19-30, 2015.

[2] I. Tomac and M. Sauter, "A review on challenges in the assessment of geomechanical rock performance for deep geothermal reservoir development," Renewable and Sustainable Energy Reviews, vol. 82, no. 3, pp. 3972-3980, 2018.

[3] H. Xie, M. Gao, R. Zhang, G. Peng, W. Wang, and A. Li, "Study on the mechanical properties and mechanical response of coal mining at $1000 \mathrm{~m}$ or deeper," Rock Mechanics and Rock Engineering, vol. 52, no. 5, pp. 1475-1490, 2019.

[4] M. Z. Gao, R. Zhang, J. Xie, G. Y. Peng, B. Yu, and P. G. Ranjith, "Field experiments on fracture evolution and correlations between connectivity and abutment pressure under top coal caving conditions," International Journal of Rock Mechanics and Mining Sciences, vol. 111, pp. 84-93, 2018.

[5] Z. Q. He, L. Chen, and T. Lu, "The optimization of pressure controller for deep earth drilling," Thermal Science, vol. 23, p. 123, 2019.

[6] G. Angeli and B. Alberini, "A comparison of radiated energy from diamond-impregnated coring and reverse-circulation 
percussion drilling methods in hard-rock environments," Geophysics, vol. 80, no. 4, pp. 13-23, 2015.

[7] M. Gao, Z. Zhang, Y. Xiangang, C. Xu, Q. Liu, and H. Chen, "The location optimum and permeability-enhancing effect of a low-level shield rock roadway," Rock Mechanics and Rock Engineering, vol. 51, no. 9, pp. 2935-2948, 2018.

[8] D. Xiangang, P. G. Ranjith, and M. S. A. Perera, "The brittleness indices used in rock mechanics and their application in shale hydraulic fracturing: a review," Journal of Petroleum Science and Engineering, vol. 143, pp. 158-170, 2016.

[9] J. Tian, J. Li, W. Cheng et al., "Working mechanism and rockbreaking characteristics of coring drill bit," Journal of Petroleum Science and Engineering, vol. 162, pp. 348-357, 2018.

[10] R. Zhang, G.-S. Li, and S.-C. Tian, "Stress distribution and its influencing factors of bottom-hole rock in underbalanced drilling," Journal of Central South University, vol. 25, no. 7, pp. 1766-1773, 2018.

[11] C. Ljunggren, Y. Chang, T. Janson, and R. Christiansson, "An overview of rock stress measurement methods," International Journal of Rock Mechanics and Mining Sciences, vol. 40, no. 78, pp. 975-989, 2003.

[12] P. Yan, Q. He, W. Lu, Y. He, W. Zhou, and M. Chen, “Coring damage extent of rock cores retrieved from high in-situ stress condition: a case study," KSCE Journal of Civil Engineering, vol. 21, no. 7, pp. 2946-2957, 2017.

[13] F.-Q. Gong, X.-F. Si, X.-B. Li, and S.-Y. Wang, "Experimental investigation of strain rockburst in circular caverns under deep three-dimensional high-stress conditions," Rock Mechanics and Rock Engineering, vol. 52, no. 5, pp. 1459-1474, 2019.

[14] F. Q. Gong, W. X. Wu, T. B. Li, and X. F. Si, "Experimental simulation and investigation of spalling failure of rectangular tunnel under different three-dimensional stress states," International Journal of Rock Mechanics and Mining Science, vol. 122, Article ID 104081, 2019.

[15] W. Wang, J.-G. Deng, B.-H. Yu, X.-J. Zheng, C.-L. Yan, and Y. Deng, "Coupled effects of stress damage and drilling fluid on strength of hard brittle shale," Journal of Central South University, vol. 23, no. 12, pp. 3256-3261, 2016.

[16] M. Z. Gao, S. Zhang, J. Li, and H. Y. Wang, "Dynamic failure mechanism of coal and gas outbursts and response mechanism of support structure," Thermal Science, vol. 23, p. 122, 2019.

[17] X. P. Li, B. Wang, and G. L. Zhou, "Research on distribution rule of geostress in deep stratum in Chinese mainland," Chinese Journal of Rock Mechanics and Engineering, vol. 31, no. S1, pp. 2875-2880, 2012, in Chinese.

[18] Y. Li and W. Q. Li, Innovative Design Methods, Science Press, Beijing, China, 2012, in Chinese.

[19] I. M. Ilevbare, D. Probert, and R. Phaal, "A review of TRIZ, and its benefits and challenges in practice," Technovation, vol. 33, no. 2-3, pp. 30-37, 2013.

[20] Č. Marcel, K. Róbert, and H. Slavomír, "Use the method of TRIZ in optimizing automated machine for ultrasonic welding," Procedia Engineering, vol. 192, pp. 80-85, 2017.

[21] A. Czinki and C. Hentschel, "Solving complex problems and TRIZ," Procedia CIRP, vol. 39, pp. 27-32, 2016.

[22] W. Xia, K. Wang, Y. Li, and Y. Xiong, "Innovative design for adaptive detection module of in-pipe robot based on TRIZ," Journal of Mechanical Engineering, vol. 52, no. 5, pp. 58-67, 2016, in Chinese.

[23] X. Guo, J. Wang, W. Zhao, K. Zhang, and C. Wang, "Study of medical device innovation design strategy based on demand analysis and process case base," Multimedia Tools and Applications, vol. 75, no. 22, pp. 14351-14365, 2016.

[24] S. D. Savransky, Engineering of Creativity: Introduction to TRIZ Methodology of Inventive Problem Solving, CRC Press, Boca Raton, FL, USA, 2000.

[25] Z. H. Bai, S. Zhang, and M. Ding, "Research on product innovation design of modularization based on theory of TRIZ and axiomatic design," Advances in Mechanical Engineering, vol. 10, no. 12, pp. 1-15, 2018.

[26] D. Chybowska and L. Chybowski, "A review of triz tools for forecasting the evolution of technical systems," Management Systems in Production Engineering, vol. 27, no. 3, pp. 174-182, 2019.

[27] J. J. Wu, S. H. Zhang, and L. Shi, "Design and application of small diameter of drill tools with dual hydraulic circulation in double tube," Journal of Central South University: Science and Technology, vol. 45, no. 1, pp. 186-192, 2014, in Chinese. 